\title{
Study of cases of post-partum hemorrhage after spontaneous vaginal delivery in labour room of obstetrics and gynecology department of tertiary care center, Ranchi, Jharkhand, India
}

\author{
Bratati Moitra*, Bullu Priya Oraon
}

Department of Obstetrics and Gynecology, Rajendra Institute of Medical Sciences, Ranchi, Jharkhand, India

Received: 14 December 2019

Revised: 19 February 2020

Accepted: 26 February 2020

\author{
*Correspondence: \\ Dr. Bratati Moitra, \\ E-mail: bgs2104@yahoo.co.in
}

Copyright: (c) the author(s), publisher and licensee Medip Academy. This is an open-access article distributed under the terms of the Creative Commons Attribution Non-Commercial License, which permits unrestricted non-commercial use, distribution, and reproduction in any medium, provided the original work is properly cited.

\begin{abstract}
Background: Postpartum haemorrhage is one of the common causes of maternal death worldwide. Whenever the amount of blood loss from or into genital tract is $500 \mathrm{ml}$ or more after delivery of baby or any amount of bleeding that makes patients haemodynamically unstable is post-partum haemorrhage.

Methods: In this study amount of blood loss after spontaneous vaginal delivery was measured in 100 cases by calibrated blood drape. Patients having high risk criteria for PPH were excluded.

Results: In this study 55\% patients were from $20-30$ years age group. $82 \%$ cases were nontribal. $94 \%$ belonged to lower middle class. $67 \%$ patients were primigravida. $89 \%$ patients had atonic $\mathrm{PPH}$ and $11 \%$ had traumatic $\mathrm{PPH}$. $85 \%$ patients had mild PPH. $60 \%$ of atonic PPH was managed by oxytocin only. $10 \%$ required oxytocin + Methergin, $6 \%$ required oxytocin + Methergin + Misoprostol. $6 \%$ required Oxytocin + Methergin + Misoprostol + Carboprost. In this study surgical intervention was required in $18 \%$ cases. Blood transfusion was required in $74 \%$ cases. $75 \%$ cases were from non-tribal ethnicity.

Conclusions: PPH is a life-threatening condition. If it can be diagnosed early and managed properly then many maternal lives can be saved. In this study there was no maternal death.
\end{abstract}

Keywords: Post-partum hemorrhage atonic, Tamponad, Traumatic post-partum hemorrhage, Uterotonics

\section{INTRODUCTION}

Haemorrhage is the number one cause of maternal death worldwide. Among all type of haemorrhages, postpartum haemorrhage is the commonest cause of maternal death. There is one death every 10 minutes somewhere in world due to PPH. ${ }^{1}$ WHO estimates that PPH accounts for nearly $30 \%$ at maternal death worldwide with an estimated 20 million deaths annually. ${ }^{2}$ Blood loss from or into genital tract more than $500 \mathrm{ml}$ after birth of baby is called post-partum haemorrhage. Clinical definition is any amount of blood loss after childbirth which makes women haemodynamically unstable, amounts to PPH. When bleeding is within $500-1000 \mathrm{ml}$ it is mild PPH. Bleeding more than $1000 \mathrm{ml}$ amounts to severe PPH. $\mathrm{PPH}$ is divided into primary and secondary. When bleeding occurs within 24 hours it is primary PPH and when bleeding occurs beyond first 24 hours up to 12 weeks it's is secondary PPH. ${ }^{3}$ Primary PPH may be due to a tonicity, cervical tear, vaginal tear, para urethral tear, retained placental beats or coagulopathy. Actual blood loss after delivery is difficult to measure. Toledo and colleagues have shown that calibrated drape with marking improved estimation accuracy. ${ }^{4}$ 
Routine active management of third stage of labour is a prophylactic measure to prevent PPH. AMTSL comprises of 10 units oxytocin IM within 1-2 minutes of delivery after excluding second baby of twin, delayed cord clamping and delivery of placenta by controlled cord traction and uterine massage. AMTSL reduces incidence of PPH and maternal mortality by $40 \% .^{3}$ Oxytocin is the drug of choice for AMTSL. Other uterotonic used for management of PPH are ergometrine (after excluding hypertension and heart disease), carboplast (after excluding bronchial asthma) and Misoprostol. In addition to the above medicines, the 2009 and 2012 WHO Guidelines for managing $\mathrm{PPH}$, mentioned carbetocin, recombinant F-VIIa and tranexamic acid as possible therapeutic interventions for PPH. ${ }^{3}$ Historically PPH was one of the leading cause of maternal deaths in the industrialized nations up to second world war. ${ }^{5}$ The first uterotonic drugs were ergot alkaloids, followed by oxytocin and finally prostaglandins. ${ }^{6}$ High quality evidence showed that calibrated blood drapes were better than measuring the blood and blood soaked materials at detecting blood loss at least $500 \mathrm{ml}^{7}$

Objective of this study was to know incidence of PPH, it's type, age and parity and ethnic distribution. To know Incidence of severe PPH, its response to medical method of treatment by uterotonics, and to know number of cases requiring surgical management and overall outcome.

\section{METHODS}

Present study is a cross sectional study carried out in labour room of department of obstetrics and gynecology, Rajendra Institute of Medical Sciences, Ranchi. Study duration from April 2018 to September 2019.

A total 100 cases of PPH after normal vaginal delivery in labour room of RIMS, Ranchi. Patients were selected randomly.

\section{Inclusion criteria}

- $\quad$ Patient having PPH after normal vaginal delivery.

\section{Exclusion criteria}

- High risk cases for PPH e.g.- pre-eclampsia, eclampsia, twin pregnancy, anaemia, jaundice, intrauterine fetal death, placenta previa, hydramnios, blood coagulopathy.

The angle between the ultrasound beam and direction of Estimation of blood loss after delivery of baby was done by a calibrated blood drape. Blood drape is a plastic sheet with a calibrated pocket to measure blood loss. Blood drape is placed beneath the buttock of women just before delivery.

PPH with flabby uterus means atonic PPH and PPH with contracted uterus is traumatic PPH. Sometimes it is combined type. The golden first hour is the time at which resuscitation must begin to achieve maximum survival before metabolic acidosis sets in. ${ }^{8} \mathrm{PPH}$ was managed according to protocol of management of PPH : shout for help, two big bore IV cannula (No. 16,18) was put, blood samples taken and blood requisition was given to patient (depending on requirement) either normal saline or Ringers lactate was started fast from one side and from other side Ringers lactate with 20 units of oxytocin was started at the rate of 40-60 drops per minute. Uterine massage is started in atonic PPH. Foley's catheterization was done. Gradually dose of oxytocin was increased if uterus was still flabby. In 24 hours maximum 3 units of oxytocin drip or maximum 100 units of oxytocin can give. Other drugs used were Methergin $(0.2 \mathrm{mg}) \mathrm{IV} / \mathrm{IM}$ excluding hypertension and heart disease. Maximum 5 doses in 24 hours can be given. Carboprost acts as a smooth muscle stimulant and is recognized second line agent for use in the management of postpartum uterine atony unresponsive to oxytocin or ergometrine, 250 microgram IM stat is given. ${ }^{9}$ It can be repeated every 15 minutes up to 8 doses if required. Contra indication of Carboprost is Bronchial asthma. Other drugs used was misoprostol 1000 microgram given per rectally. If PPH is suspected to be traumatic or atonic PPH not responding to uterotonics then patient was shifted to OT. Cervical visualization was done, under anaesthesia uterine exploration was done for retained placental bits. Repair of cervical tear was done if cervical tear was detected.

If PPH was still not controlled, then bimanual uterine compression was tried. Balloon tamponade was done in some cases with condom catheter. Some cases required laparotomy followed by uterine artery ligation. In 4 cases of severe PPH not responding to oxytocic and other method - including surgical methods of stepwise devascularisation, subtotal hysterectomy was done as life saving measure. Routine use of active management of third stage of labour for all vaginal singleton births in health facilities is recommended by FIGO and ICM as well as by WHO. ${ }^{10}$

\section{Statistical analysis}

Data is entered in MS excel and analyzed BY IBMSPSS statistical version 20 data editor. Frequency and chi square test performed for categorical variables.

\section{RESULTS}

Table 1 shows incidence of PPH was more in age group of 20-30 years. Followed by age group of $<20$ years, $55 \%$ and $41 \%$ respectively. This may be due to the fact that maximum number of patients in this study was between 20-30 years.

A total $33 \%$ of patients were literate.

A total $82 \%$ of patients are non-tribal. Ethnicity may have some role in PPH and needs further research. This may 
also be due to the fact that majority of patients included in the study were nontribal (Table 2).

Table 1: Distribution of cases according to age of patients.

\begin{tabular}{|lll|}
\hline Age group & Frequency & Percent \\
\hline$<20$ years & 41 & $41.0 \%$ \\
\hline $20-30$ years & 55 & $55.0 \%$ \\
\hline$>30$ years & 4 & $4.0 \%$ \\
\hline Total & 100 & $100.0 \%$ \\
\hline
\end{tabular}

Table 2: Distribution of cases according to ethnicity.

\begin{tabular}{|lll|}
\hline Ethnicity7 & Frequency & Percent \\
\hline Non-tribal & 82 & $82.0 \%$ \\
\hline Valid & & \\
\hline Tribal & 18 & $18.0 \%$ \\
\hline Total & 100 & $100.0 \%$ \\
\hline
\end{tabular}

A total $94 \%$ cases belonged to lower middle class. Poor nutritional status may be responsible for increased incidence of PPH. $4 \%$ patients were from lower class and $1 \%$ each from upper class and upper middle class (Table 3 ).

Table 3: Distribution of case according to socioeconomic status.

\begin{tabular}{|lll|}
\hline Socioeconomic status & Frequency & Percent \\
\hline Upper class & 1 & $1.0 \%$ \\
\hline Upper middle class & 1 & $1.0 \%$ \\
\hline Lower middle class & 94 & $94.0 \%$ \\
\hline Lower class & 4 & $4.0 \%$ \\
\hline Total & 100 & $100.0 \%$ \\
\hline
\end{tabular}

Table 4: Distribution of cases of parity.

\begin{tabular}{|lll|}
\hline Parity & Frequency & Percent \\
\hline Primigravida & 67 & $67.0 \%$ \\
\hline Multigravida & 33 & $33.0 \%$ \\
\hline Total & 100 & $100.0 \%$ \\
\hline
\end{tabular}

Table 5: Distribution of cases according to types of PPH.

\begin{tabular}{|lll|}
\hline Type of PPH & Frequency & Percent \\
\hline Traumatic & 11 & $11.0 \%$ \\
\hline Atonic & 89 & $89.0 \%$ \\
\hline Total & 100 & $100.0 \%$ \\
\hline
\end{tabular}

A total $67 \%$ of patients were primigravida and $33 \%$ were multigravida. This result does not tally with the fact that PPH is commoner in multigravida. It may be incidental finding as more primigravida patients were included in this study. Incidence in primigravida was 33\% (Table 4). A total $89 \%$ cases had atonic PPH and $13 \%$ cases had traumatic PPH. This tallies with previous studies that atonic PPH is commoner than traumatic PPH (Table 5).
A total $85 \%$ of patient had mild PPH and $15 \%$ of patient had severe $\mathrm{PPH}$

Table 6: Distribution of cases according to amount of blood loss.

\begin{tabular}{|lll|}
\hline Amount of blood loss & Frequency & Percent \\
\hline $500-1000 \mathrm{ml}$ & 85 & $85.0 \%$ \\
\hline $1000-1500 \mathrm{ml}$ & 15 & $15.0 \%$ \\
\hline
\end{tabular}

Table 7: Distribution according to cases who responded to medical management done in PPH.

\begin{tabular}{|lll|}
\hline & Frequency & Percent \\
\hline Oxytocin & 60 & $60.0 \%$ \\
\hline Oxytocin+Methergin & 10 & $10.0 \%$ \\
\hline $\begin{array}{l}\text { Valid Oxytocfin } \\
\text { +Methergin+Misoprostol }\end{array}$ & 6 & $6.0 \%$ \\
\hline $\begin{array}{l}\text { Oxytocin+Methergin+Miso } \\
\text { prostol+Carboprost }\end{array}$ & 6 & $6.0 \%$ \\
\hline Total & 82 & $82.0 \%$ \\
\hline
\end{tabular}

A total $60 \%$ patients of atonic PPH were managed by oxytocin only. $10 \%$ cases of atonic $\mathrm{PPH}$ required oxytocin + Methergin $6 \%$ cases required oxytocin + Methergin + Misoprost and 6\% cases required. Oxytocin + Methergin + Misoprostal + Carboprost (Table 7).

Table 8: Distribution of cases according to surgical management.

\begin{tabular}{|lll|}
\hline Surgical management & Frequency & Percent \\
\hline Not required & 82 & $82.0 \%$ \\
\hline Cervical tear repair & 11 & $11.0 \%$ \\
\hline Uterine artery ligation & 3 & $3.0 \%$ \\
\hline Subtotal hysterectomy & 4 & $4.0 \%$ \\
\hline Total & 100 & $100.0 \%$ \\
\hline
\end{tabular}

A total $9 \%$ cases required uterine balloon tamponade. $11 \%$ case cervical tear was repaired, $3 \%$ case uterine artery ligation was required, and $4 \%$ cases hysterectomy was done (Table 8).

Table 9: Distribution of cases according to requirement of blood transfusion.

\begin{tabular}{|lll|}
\hline Blood transfusion & Frequency & Percent \\
\hline Yes & 74 & $74.0 \%$ \\
\hline Not required & 26 & $26.0 \%$ \\
\hline Total & 100 & $100.0 \%$ \\
\hline
\end{tabular}

A total $74 \%$ of patient require blood transfusion whereas $26 \%$ of patient were required volume expansion by crystalloid and colloids. This corresponds with the fact that majority of patients in the study had mild PPH (Table 9).

In non-tribal group $91.4 \%$ had mild PPH whereas $8.8 \%$ had severe PPH where as in tribal group $63.36 \%$ patients 
had mild PPH where as $36.4 \%$ patients had severe PPH. This shows that incidence of mild PPH was more in nontribal group. Incidence of severe PPH is more in tribal population. It may be due to small number of tribal patients in this study. Further study with larger sample size is required (Table 10).
Among primigravida patients $91.2 \%$ had mild PPH and $8.8 \%$ had severe PPH whereas among multigravida patient $72.6 \%$ had mild PPH and $27.4 \%$ had severe PPH. Incidence of mild PPH was more in primigravida. Incidence of severe PPH was more in multigravida (Table 11).

Table 10: Correlation between ethnicity and amount of blood loss measured by blood drape.

\begin{tabular}{|c|c|c|c|c|c|}
\hline & \multicolumn{4}{|c|}{ Amount of blood loss measured by blood drape } & \multirow{2}{*}{ Total } \\
\hline & $500-1000 \mathrm{ml}$ & & & & \\
\hline Non-tribal & 75 & $91.4 \%$ & 7 & $8.8 \%$ & 82 \\
\hline \multicolumn{6}{|l|}{ Ethnicity } \\
\hline Tribal & 11 & $63.6 \%$ & 7 & $36.4 \%$ & 18 \\
\hline Total & 86 & & 14 & & 100 \\
\hline
\end{tabular}

$\mathrm{p}$ value $=0.001$.

Table 11: Correlation between parity and amount of blood loss measured by blood drape.

\begin{tabular}{|llllll|}
\hline \multirow{2}{*}{ Parity } & \multicolumn{2}{l}{ A mount of blood loss measured by blood drape } & Total \\
\hline Primigravida & $\mathbf{5 0 0 - 1 0 0 0 ~} \mathbf{~ m l}$ & $\mathbf{1 0 0 0 - 1 5 0 0 ~} \mathbf{~ m l}$ & $8.8 \%$ & 67 \\
\hline Multigravida & 61 & $91.2 \%$ & 6 & $27.4 \%$ & 33 \\
\hline Total & 24 & $72.6 \%$ & 9 & 15 & 100 \\
\hline
\end{tabular}

\section{DISCUSSION}

The mean age was 27.7 year in a study conducted by Solwayo Ngwenya on PPH: incidence risk factors and outcome at Mpilo hospital in Zimbave, for a duration from January 2016 to June $2016 .{ }^{11}$ In this study PPH was found to be more common in 20-30 years age group. 55\% of patients were between 20-30 years age group whereas A total $41 \%$ were of less than 20 years age group. This may be due to the fact that majority of patients were from this age group.

A total $82 \%$ of patients were nontribal whereas $18 \%$ patients were tribal.

A total $94 \%$ patients were from lower middle class. This finding tallies with the fact that poor nutritional status may be responsible for higher incidence of PPH in this class of patients.

A total $67 \%$ patients were primigravida whereas $33 \%$ were multigravida. This is contrary to the finding of other studies where $\mathrm{PPH}$ is commoner in multigravida. This may be due to the fact that majority of patients included in the study were primigravida. This may be an incidental finding.

In this study $89 \%$ cases were of atonic PPH and $11 \%$ were traumatic PPH. This tallies with previous studies.

Incidence of mild PPH was $85 \%$ patients and incidence of severe PPH was $15 \%$.
In a study conducted by Sheldon WR et al, on postpartum hemorrhage, risk, and maternal outcome: findings from WHO multi-country survey on maternal and new-borne health from $1^{\text {st }}$ May 2010 to $31^{\text {st }}$ December 2011 in 28 countries, of total 274985 deliveries, among cases of PPH $92.7 \%$ received uterotonics for treatment. ${ }^{12}$ In this study $60 \%$ patients of atonic PPH were managed by to oxytocin only, $10 \%$ of cases of atonic PPH required Oxytocin + Methergin, $6 \%$ cases required Oxytocin + Methergin + Misoprostol, $6 \%$ required carboprost in addition to Oxytocin + Methergin + Misoprostal.

A total $18 \%$ of cases required surgical management. Cervical tear repair was done in $11 \%$ cases, uterine artery ligation was done in $3 \%$ cases and subtotal hysterectomy was done in $4 \%$ cases. Blood transfusion was required in $74 \%$ cases. $26 \%$ cases were managed by volume expansion by crystalloids and colloids.

Among 82 cases of non-tribal ethnicity 75 had mild PPH and 7 had mild PPH. Among 18 tribal patients 11 had mild PPH and 7 had severe PPH. Among 67 primigravida 61 had mild PPH and 6 had severe PPH. Among 33 multigravida patients 24 had mild $\mathrm{PPH}$ and 9 had severe PPH.

\section{CONCLUSION}

In this study uterine atony followed by traumatic PPH was most common cause of PPH. PPH is leading and most preventable cause of maternal mortality. Incidence 
of PPH was found to be more in non-tribal. Tribal may be ethnically protected from PPH but it needs further research.

\section{Funding: No funding sources}

Conflict of interest: None declared

Ethical approval: The study was approved by the Institutional Ethics Committee

\section{REFERENCES}

1. Weeks A. The prevention and treatment of postpartum haemorrhage: what do we know, and where do we go to next?. BJOG: An Inter J Obstet Gynaecol. 2015;122(2):202-10.

2. Deka D, Mishra R. Post-partum hemorrhage. Ian Donalds practical obstetrics problem Wolters Kluwer, $7^{\text {th }}$ ed; 2014:611-625.

3. WHO guidelines for management of postpartum hemorrhage and retained placenta word health organization; 2009. Available at: https://apps.who.int/iris/bitstream/handle/10665/441 71/9789241598514_eng.pdf;jsessionid=0B0C538925 1F4B230D45B8CF9AA6ED80? sequence $=1$. Accessed on $12^{\text {th }}$ September 2019.

4. Bloom CL, Roose H, Spong. Obstetrical hemorrhage. William's obstetrics McGrawHill $23^{\text {rd }}$ ed; 2010:759-796.

5. El-Refaey H, Rodeck C. Post-partum haemorrhage: definitions, medical and surgical management. A time for change. British medical bulletin. 2003;67(1):205-17.

6. Unterscheider J, Breathnach F, Geary M. Standard Medical Therapy for post-partum hemorrhage 48:355. Available at: http//glowm.com/poit/PPH2nd-edn- chap-43 pdf. Accessed on $12^{\text {th }}$ September 2019.
7. Cochrane DIAZV, Abalos E, Carroli G. Methods of estimating blood loss after vaginal birth to improve maternal outcomes. Cochrane Database Syst Rev. 2018;9:CD010980.

8. Arias F, Bhide AG, Arulkumaran S, Damania K, Daftary SN. Eds. Practical Guide to High Risk Pregnancy and Delivery-E-Book. $4^{\text {th }}$ ed. Elsevier Health Sciences; 2012:390-392,395.

9. Baduni N, Sanwal MK, Jain A. Acute pulmonary edema after intra-myometrial prostodin. J Anaesthesiol Clin Pharmacol. 2011;27(2):275.

10. Stanton C, Armbruster D, Knight R, Ariawan I, Gbangbade S, Getachew A, et al. Use of active management of the third stage of labour in seven developing countries. 2009:207-15.

11. Ngwenya S. Postpartum hemorrhage: incidence, risk factors, and outcomes in a low-resource setting. International journal of women's health. 2016;8:647.

12. Sheldon W, Blum J, Vogel JP, Souza JP, Gülmezoglu AM, Winikoff B. WHO multicountry survey on maternal and newborn health research network. Postpartum haemorrhage management, risks, and maternal outcomes: findings from the World Health Organization Multicountry Survey on Maternal and Newborn Health. Inter J Obstet Gynaecol. 2014;121:5-13.

Cite this article as: Moitra B, Oraon BP. Study of cases of post-partum hemorrhage after spontaneous vaginal delivery in labour room of obstetrics and gynecology department of tertiary care center, Ranchi, Jharkhand, India. Int J Reprod Contracept Obstet Gynecol 2020;9:1540-4. 